heterogeneity of $\mathrm{I}^{2}=94 \% \mathrm{P}<0.01$ (IDDF2021-ABS-0117 Figure 2). In FAP the total prevalence of pouchitis was found to be 0.02 (95\% CI: 0.00-0.14) with a significant heterogeneity of $\mathrm{I}^{2}=69 \%, \mathrm{P}<0.01$ (IDDF2021-ABS-0117 Figure 3). The odds ratio of total pouchitis in UC compared with FAP patients was 3.78 (CI: 2.76-5.34, p<0.001).

Conclusions Our findings support the consensus that the prevalence of pouchitis is higher in UC than in FAP and higher in acute than in chronic. More significantly, our findings suggest that the true prevalence of pouchitis is higher than commonly reported in the literature. This literature may help counsel patients prior to undergoing restorative proctocolectomy, especially in those with ulcerative colitis who have often had to live for many years with the consequences of colonic mucosal inflammation.

\section{IDDF2021-ABS-0119 THERMAL ABLATION OF MUCOSAL DEFECT MARGINS AFTER ENDOSCOPIC MUCOSAL RESECTION REDUCES ADENOMA RECURRENCE: A SYSTEMATIC REVIEW AND META-ANALYSIS}

Nikko Theodore Raymundo*, Joseph Erwin Dumagpi, Tim Lin, Jonard Co. Institute of Digestive and Liver Diseases, St. Luke's Medical Center, Global City, Philippines

\subsection{6/gutjnl-2021-IDDF.143}

Background Resection of colorectal lesions larger than $20 \mathrm{~mm}$ is complex and requires advanced endoscopic techniques such as endoscopic mucosal resection (EMR). Adenoma recurrence is a limiting factor especially due to micro-adenomas at the margin of the EMR mucosal defect site. This systematic review and meta-analysis aimed to determine the efficacy of thermal ablation of mucosal defect margins after EMR in reducing adenoma recurrence.

Methods A comprehensive, computerized literature search from the PubMed Central, Embase, Cochrane Library, and OVID was performed with the following search terms: coagulation, mucosal defect margin, endoscopic mucosal resection, and adenoma recurrence. Three cohort studies were selected and validated using the Newcastle-Ottawa criteria. Pooled data were combined under a random-effects model. The Cochrane Review Manager Software version 5.3 was used for all analyses.

Results Three cohort studies comprising of 361 patients were analyzed. In the random-effects model, the pooled odds ratio (OR) of adenoma recurrence was 0.22 (95\% CI 0.13-0.39; I2 $=0 \%)($ IDDF2021-ABS-0119. Figure 1). The pooled data of the three studies showed a trend towards a beneficial effect of thermal ablation of mucosal defect post-endoscopic mucosal resection in reducing the risk of adenoma recurrence.

Conclusions Thermal ablation of the mucosal defect margins was shown to have a decreased risk of adenoma recurrence after endoscopic mucosal resection. However, further

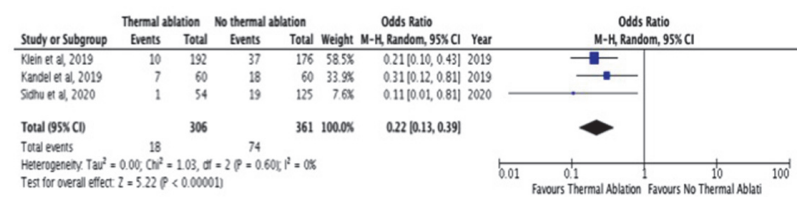

Abstract IDDF2021-ABS-0119 Figure 1 Forrest plot prospective randomized studies are recommended to confirm this relationship.

\section{IDDF2021-ABS-0120 FACE-TO-FACE INSTRUCTION AND PERSONALIZED BOWEL PREPARATION REGIMENS IMPROVE QUALITY OF PREPARATION FOR INPATIENT COLONOSCOPY: A RANDOMIZED CONTROLLED TRIAL}

${ }^{1}$ Hui Gao*, ${ }^{2}$ Cenqin Liu, ${ }^{1}$ Xin Yuan, ${ }^{3}$ Hongpeng Lu, ${ }^{4}$ Yonghong Xia, ${ }^{3}$ Zhixin Zhang, ${ }^{3}$ Zhenfei Bao, ${ }^{3}$ Weihong Wang, ${ }^{3}$ Jiarong Xie, ${ }^{3}$ Lei Xu. ${ }^{1}$ School of Medicine, Ningbo University, Ningbo, China; ${ }^{2}$ College of Medicine, Zhejiang University, Hangzhou, China; ${ }^{3}$ Department of Gastroenterology, Ningbo First Hospital, Ningbo, China; ${ }^{4}$ Department of Gastroenterology, Ninghai Second Hospital, Ningbo, China

\subsection{6/gutjpl-2021-IDDF.144}

Background Poor bowel preparation (BP) is commonly observed in inpatients undergoing colonoscopy, particularly those with a higher risk for inadequate BP. The objective of this study was to determine whether face-to-face instruction (FFI) and personalized BP regimens could improve the quality of BP for inpatient colonoscopy procedures.

Methods In this endoscopist-blinded, randomized controlled trial, 320 inpatients were enrolled and randomly allocated at a ratio of $1: 1$ to the control and intervention groups. The intervention group received FFI and personalized BP regimes, while the control group received the standard education and $\mathrm{BP}$ regimes. The primary outcome was an adequate $\mathrm{BP}$ rate. Secondary outcomes included rates of procedure-related adverse events, incorrect diet restriction and laxative intake, quality of sleep before colonoscopy and willingness to repeat the BP.

Results Demographic characteristics were comparable between the control and intervention groups. Notably, the adequate BP rate in the FFI group was significantly higher compared to the control group [intention-to-treat (ITT) analysis: $70.0 \%$ vs. 51.3\%, $P<0.001$; per-protocol $(\mathrm{PP})$ analysis: $79.4 \%$ vs. 58.6\%, $P<0.001$; (IDDF2021-ABS-0120 Figure 1. The rate of adequate BP between the FFI and control groups for inpatients following ITT and PP analyses). Bowel cleanliness was significantly improved in response to the intervention in highrisk inpatients (ITT analysis: $65 \%$ vs. $44.6 \%, P=0.004 ; \mathrm{PP}$ analysis: $73.0 \%$ vs. $51.7 \%, P=0.004$ ) and in low-risk inpatients (ITT analysis: $80 \%$ vs. $62.7 \%, P=0.037$; PP analysis: $92.3 \%$ vs. $69.8 \% P=0.003)$. There were no significant

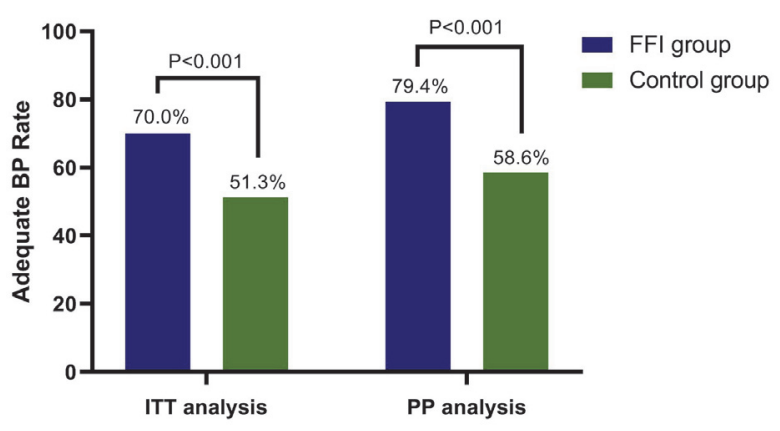

Abstract IDDF2021-ABS-0120 Figure 1 
differences between the control and intervention groups regarding secondary outcomes.

Conclusions FFI and personalized BP regimens improve the rate of adequate BP, especially in patients with a higher risk for inadequate BP. As such, inpatients would benefit from this novel approach for better BP to ultimately improve the quality of colonoscopies.

\section{IDDF2021-ABS-0121 CLINICAL AND SUBCLINICAL CHARACTERISTICS OF ACUTE PERIPANCREATIC FLUID COLLECTIONS IN ACUTE PANCREATITIS}

Anh Tran Ngoc*, Thanh Duong Cong, Nhan Do Hong. Hanoi Medical University Hospital, Vietnam

\subsection{6/gutjnl-2021-IDDF.145}

Background Acute peripancreatic fluid collection is the most frequent complication of acute pancreatitis, 30\% - 50\%.

Objectives To investigate the clinical and subclinical characteristics of acute peripancreatic fluid collections in acute pancreatitis and some factors related to the formation of acute peripancreatic fluid collections

Methods A prospective descriptive study of 117 patients diagnosed with acute pancreatitis with acute peripancreatic fluid collections according to the 2012 revised Atlanta classification at Hanoi Medical University Hospital from August 2018 to June 2021.

Results The mean age of patients in the study group was 42 years old. Ratio male/female: $8 / 1$. The proportion of alcoholic etiology $(60 \%)$ in patients with acute peripancreatic fluid collections was significantly higher compared to other etiologies ( $\mathrm{p}<0.01$ ). Abdominal pain was found in $100 \%$ of patients (IDDF2021-ABS-0121 Figure 1. Clinical symptoms in the group with acute peripancreatic fluid collections). The level of pain according to VAS scale on admission in grade $\mathrm{E}$ was significantly higher, compared in grade D $(5.2 \pm 1.3$ vs. $4.6 \pm$ 1.2, $\mathrm{p}<0.01)$. Abdominal distention, fever, organ failure in grade $\mathrm{E}$ were significantly higher than in grade $\mathrm{D}$, respectively

\begin{tabular}{|c|c|c|c|c|}
\hline Variable & $\begin{array}{l}\text { Total } \\
(\mathrm{N}=117)\end{array}$ & $\begin{array}{l}\text { Grade } D \\
(\mathrm{~N}=61)\end{array}$ & $\begin{array}{l}\text { Grade } E \\
(\mathrm{~N}=56)\end{array}$ & $\mathrm{p}$-value \\
\hline Abdominal distention & $82.1 \%$ & $75.4 \%$ & $91.1 \%$ & 0.025 \\
\hline Fever & $38.5 \%$ & $29.5 \%$ & $48.2 \%$ & 0.038 \\
\hline $\begin{array}{l}\text { Abdominal wall } \\
\text { resistance }\end{array}$ & $25.6 \%$ & $19.7 \%$ & $32.1 \%$ & 0.123 \\
\hline Abdominal pain (VAS) & $4.9 \pm 1.3$ & $4.6 \pm 1.2$ & $5.2 \pm 1.3$ & 0.009 \\
\hline CRPhs (mg/dl) & $11.2 \pm 11.8$ & $9.4 \pm 10.1$ & $13.2 \pm 13.2$ & 0.147 \\
\hline Hematocrit (\%) & $44.6 \pm 5.0$ & $43.8 \pm 3.8$ & $45.5 \pm 5.9$ & 0.070 \\
\hline White blood cell (G/L) & $13.6 \pm 4.2$ & $13.2 \pm 4.1$ & $14.0 \pm 4.3$ & 0.301 \\
\hline Calcium (mmoll) & $2.1 \pm 0.2$ & $2.2 \pm 0.1$ & $2.0 \pm 0.3$ & 0.000 \\
\hline Blood urea $(\mathrm{mmol} / \mathrm{l})$ & $4.2 \pm 2.0$ & $4.1 \pm 1.5$ & $4.4 \pm 2.6$ & 0.784 \\
\hline Creatinin $(\mu \mathrm{mol} / \mathrm{l})$ & $70.6 \pm 24.9$ & $71.3 \pm 21.3$ & $69.8 \pm 28.7$ & 0.213 \\
\hline Lactat (mmol/l) & $2.5 \pm 1.5$ & $2.2 \pm 1.1$ & $2.8 \pm 1.7$ & 0.069 \\
\hline LDH (IU/L) & $236.0 \pm 201.0$ & $186.6 \pm 96.7$ & $281.3 \pm 255.8$ & 0.010 \\
\hline Amylase (IU/L) & $565.0 \pm 719.1$ & $501.3 \pm 728.4$ & $629.9 \pm 710.6$ & 0.004 \\
\hline
\end{tabular}

LDH lactate dehydrogenase
$91.1 \%$ vs. $75.9 \%, 48.2 \%$ vs $29.5 \%, 16.1 \%$ vs $4.9 \%$, p < 0.05. (IDDF2021-ABS-0121 Table 1, IDDF2021-ABS-0121 Table 2). Serum calcium levels in grade $E$ was significantly lower than in grade $\mathrm{D}(2.0 \pm 0.3$ vs $2.2 \pm 0.1 \mathrm{mmol} / \mathrm{l}, \mathrm{p}<$ $0.01)$. LDH was significantly higher in grade E, compared to grade $\mathrm{D}, 281.3 \pm 255.8$ vs $186.6 \pm 96.7 \mathrm{IU} / \mathrm{L}, \mathrm{p}<0.05$. (IDDF2021-ABS-0121 Table 1, IDDF2021-ABS-0121 Table 2). SIRS score $\geq 2$ and HAPS $>0$ had high rates of $73.3 \%$ and

\begin{tabular}{|c|c|c|c|c|c|}
\hline \multicolumn{2}{|l|}{ Complications } & \multirow{2}{*}{$\begin{array}{l}\text { Total } \\
(\mathrm{N}=117)\end{array}$} & \multirow{2}{*}{$\begin{array}{l}\text { Grade D } \\
(\mathrm{N}=61) \\
0\end{array}$} & \multirow{2}{*}{$\begin{array}{l}\text { Grade } E \\
(\mathrm{~N}=56)\end{array}$} & \multirow[t]{2}{*}{ p-value } \\
\hline $\begin{array}{l}\text { Abdominal } \\
\text { complications }\end{array}$ & Thrombosis & & & & \\
\hline \multirow[t]{3}{*}{ Organ failure } & Total & $12(10.2 \%)$ & $3(4.9 \%)$ & $9(16.1 \%)$ & 0.047 \\
\hline & $\begin{array}{l}\text { Respiratory } \\
\text { failure }\end{array}$ & $10(8.5 \%)$ & $2(3.3 \%)$ & $8(14.3 \%)$ & \\
\hline & Renal failure & $2(1.7 \%)$ & $1(1.6 \%)$ & $1(1.8 \%)$ & \\
\hline
\end{tabular}

Abstract IDDF2021-ABS-0121 Table 3 CT grading of acute peripancreatic fluid collections according to severity

\begin{tabular}{lllll}
\hline Variable & Total & Grade D & Grade E & p-value \\
\hline CRPhs $>15(\mathrm{mg} / \mathrm{dl})$ & $35 / 104$ & $18 / 55$ & $17 / 49$ & 0.832 \\
& $(33.7 \%)$ & $(32.7 \%)$ & $(34.7 \%)$ & \\
SIRS $\geq 2$ & $85 / 116$ & $36 / 61$ & $49 / 55$ & 0.000 \\
& $(73.3 \%)$ & $(59.0 \%)$ & $(89.1)$ & \\
HAPS $>0$ & $98 / 116$ & $48 / 61$ & $50 / 55$ & 0.069 \\
& $(84.5 \%)$ & $(78.7 \%)$ & $(90.9 \%)$ & \\
BISAP $\geq 3$ & $5 / 116$ & $2 / 61$ & $3 / 55$ & 0.667 \\
& $(4.3 \%)$ & $(3.3 \%)$ & $(5.5 \%)$ & \\
JSS $\geq 3$ & $19 / 70$ & $7 / 31$ & $12 / 39$ & 0.444 \\
& $(27.1 \%)$ & $(22.6 \%)$ & $(30.8 \%)$ & \\
\hline
\end{tabular}

SIRS systemic inflammatory response syndrome, HAPS harmless acute pancreatitis score, BISAP bedside index for severity in acute pancreatitis, JSS Japanese severity score

Abstract IDDF2021-ABS-0121 Table 4 Frequency of detecting acute peripancreatic fluid collections on ultrasound and on CT

\begin{tabular}{|c|c|c|c|c|}
\hline \multirow[b]{2}{*}{ Location } & \multicolumn{2}{|c|}{ Ultrasound ( $\mathrm{N}=71)$} & \multicolumn{2}{|l|}{$\mathrm{CT}(\mathrm{N}=117)$} \\
\hline & Frequency & Percentage (\%) & Frequency & Percentage (\%) \\
\hline $\begin{array}{l}\text { Around the } \\
\text { pancreas }\end{array}$ & 55 & 77.5 & 113 & 96.6 \\
\hline $\begin{array}{l}\text { Left anterior } \\
\text { pararenal space }\end{array}$ & 17 & 23.9 & 69 & 59 \\
\hline $\begin{array}{l}\text { Right anterior } \\
\text { pararenal space }\end{array}$ & 12 & 16.9 & 41 & 35 \\
\hline Hapatorenal recess & 11 & 15.5 & 6 & 5.1 \\
\hline Splenic hilum & 16 & 22.5 & 25 & 21.4 \\
\hline $\begin{array}{l}\text { Right paracolic } \\
\text { gutter }\end{array}$ & 17 & 23.9 & 38 & 32.5 \\
\hline Left paracolic gutter & 17 & 23.9 & 50 & 42.7 \\
\hline Mesenteric root & 6 & 8.5 & 18 & 15.4 \\
\hline Pouch of douglas & 22 & 31 & 35 & 29.9 \\
\hline Omental bursa & 1 & 1.4 & 7 & 6 \\
\hline
\end{tabular}

